Aksaray University
Journal of Science and Engineering
e-ISSN: 2587-1277
http://dergipark.gov.tr/asujse
http://asujse.aksaray.edu.tr

Research Article

\title{
Generating to Three Dimensional Models from Taken Photos in Vertical Position with Unmanned Aerial Vehicles: Aksaray University Campus Mosque
}

\author{
Ali Abdulwahed Mahmod, H. Murat Yilmaz \\ Aksaray University, Engineering Faculty, Department of Geomatics Engineering, Aksaray, 68100, Turkey \\ -Received Date: 01 Feb 2018 \\ -Revised Date:12 Apr 2018 \\ -Accepted Date: 07 Sep 2018 \\ -Published Online: 12 Dec 2018
}

\begin{abstract}
Unmanned aerial vehicles (UAVs) applications included archaeology, construction engineering, agricultural catchment and forestry. Unmanned aerial vehicle UAVs (Rotary or fixed wing), capable of performing the photogrammetric data acquisition with amateur or digital cameras, can fly in manual, semi-automated and autonomous techniques. Following a typical photogrammetric workflow, three dimensional results like Digital Surface Models or Digital Terrain Models (DSM/DTM), contours, textured 3D models, vector information, etc. can be produced, even on large areas.

In this study, a three dimensional model of the campus mosque of Aksaray University was formed with the vertical photos of UAV. Two different resolution cameras at 50 and $100 \mathrm{~m}$ altitude were obtained with $80 \%$ and $60 \%$ overlap rates for both altitudes. Using the PhotoScan software, a four-faced three-dimensional model of the mosque was created. 3D model generated for both data in lowest and medium accuracy for two different areas, and then total errors for all assessments were compared to know which altitude is the best to generating 3D model, problems in the model were discussed and the edges and elevations measured by the geodesic model were compared with those measured by the obtained model. The difference was found to vary between $2-50 \mathrm{~cm}$ after the comparison. The average error of the flight was found to be $4.85 \mathrm{~cm}$ for $50 \mathrm{~m}$ flight height and $5.16 \mathrm{~cm}$ for $100 \mathrm{~m}$ flight height. Because the Unmanned Aerial Vehicle used cannot take an oblique picture, the Mosque could not be fully modelled. The three-dimensional modelling gaps have been tried supplied with pictures taken from the ground. In the case of unmanned aerial vehicles, it is seen that three dimensional models can be made with appropriate accuracy in case that such structures are suitable picture taking.
\end{abstract}

\section{Keywords}

3D-model, Unmanned Aerial Vehicle (UAV), Aksaray University.

${ }^{*}$ Corresponding Authour: H. Murat Yilmaz, hmyilmaz@aksaray.edu.tr 


Aksaray University
Journal of Science and Engineering
e-ISSN: 2587-1277
http://dergipark.gov.tr/asujse
http://asujse.aksaray.edu.tr

Research Article

\title{
İnsansız Hava Aracı İle Dik Konumda Çekilen Resimlerle Üç Boyutlu Model Oluşturma: Aksaray Üniversitesi Kampüs Camii
}

\author{
Ali Abdulwahed Mahmod, H.Murat Yılmaz* \\ Aksaray Üniversitesi, Mühendislik Fakültesi, Harita Mühendisliği, Aksaray, 68100, Türkiye
}

-Gönderi Tarihi: 01 Şub 2018

-Düzeltme Tarihi: 12 Nis 2018

-Kabul Tarihi: 07 Eyl 2018

-Cevrimiçi Yayın Tarih: 12 Ara 2018

Özet

İnsansız hava araçları (İHA) arkeoloji, mühendislik çalışmaları, tarım havza ve orman yönetimi gibi çok geniş uygulama alanına sahiptir. Farklı özelliklere sahip fotoğraf makineleri ile fotogrametrik veri toplama yapabilen İHA 'lar manuel, yarı-otomatik ve otomatik uçuş yapabilme özelliğine sahiptir. İHA'lar ile standart bir fotogrametrik çalışmada sayısal yükseklik modeli (SYM), sayısal arazi modeli (SAM), hâlihazır haritalar, üç boyutlu obje modelleri gibi çok geniş alanlarda ürün üretilebilmektedir.

$\mathrm{Bu}$ çalışmada düşey konumda çekilmiş İHA resimleri ile Aksaray Üniversitesi Kampüs Camii'nin üç boyutlu modelinin elde edilmesi amaçlanmıştır. 50 ve $100 \mathrm{~m}$ yükseklikten iki farklı çözünürlükteki kamera ile \% 80 ve \% 60 bindirme oranlarıyla kullanılan İHA'dan elde edilen resimler ve PhotoScan yazılımı kullanılarak Camiinin dört farklı üç boyutlu modeli oluşturulmuştur. Tüm İHA görüntülerinden iki farklı alanda düşük ve orta doğrulukta $3 \mathrm{~B}$ model üretilmiş ve hangi uçuş yüksekliğinin 3B model oluşturmak için daha iyi olduğunu belirlemek için tüm analizlerde toplam hata miktarı hesaplanmış, karşılaşılan problemler tartışılmış ve binaya ait yatay ve düşey cephe ölçmeleri yapılarak oluşturulan model üzerinden alınan değerlerle karşılaştırılmıştır. Yapılan karşılaştırma sonrasında farkların $2-50 \mathrm{~cm}$ arasında değişiklik gösterdiği gözlemlenmiştir. Toplam ortalama hata $50 \mathrm{~m}$ uçuş yüksekliği için $4.85 \mathrm{~cm}, 100 \mathrm{~m}$ uçuş yüksekliği için ise $5.16 \mathrm{~cm}$ bulunmuştur. Kullanılan İnsansız Hava Aracının eğik resim çekememesi nedeniyle Camii tam olarak modellenememiştir. Yerden çekilen resimlerle üç boyutlu modeldeki boşluklar giderilmeye çalışılmıştır. İnsansız hava araçları ile bu tür yapıların uygun resim çekimi olması durumunda uygun doğrulukta üç boyutlu modellemelerinin yapılabileceği gözlenmiştir.

\section{Anahtar Kelimeler}

Üç Boyutlu Model, İnsansız Hava Aracı (İHA), Aksaray Üniversitesi

*Sorumlu Yazar: H. Murat Yılmaz, hmyilmaz@aksaray.edu.tr 


\section{GÍRİş}

Konuma dayalı veri üreten Global Konumlama Sistemleri (GPS), yersel jeodezik ölçmeler, yersel lazer tarayıcı, geleneksel hava araçları, fotogrametri ve uzaktan algılama gibi çeşitli yöntemler vardır. İnsansız Hava Araçları (İHA) da konuma dayalı doğru ve hassas veri üretebilen bir teknolojidir. İHA'lar gelecekte birçok disipline veri üreten en önemli veri kaynağ1 olacaktır [1].

İnsansız Hava Araçları (İHA), uzaktan kontrol edilebilir, yarı otomatik veya tam otomatik tekniklerde uçabilmekte ve kamera, sensör, kominikasyon ekipmanları veya diğer ekipmanları taşıyabilmektedir. İHA'lar klasik insanlı hava taşıtlarından çok daha küçük bir yapıya sahiptir bu nedenle taşıması çok kolay ve daha ekonomiktir. İHA' ların operasyonel savaş güçlerine önemli katkıları da bulunmaktadır [2].

Sanal gerçeklik, haberleşme, otomatik yönlendirme gibi uygulamalarda üç boyutlu (3B) model kullanılması gerekmektedir. Örneğin, endüstri kalite değerlendirilmesi sırasında, afet öncesi ve sonrası, turizm, mimarlık alanlarında ve 3B şehir planlamasında binaların 3B modelinin oluşturulması önemlidir. Bu tür çalışmalarda da İHA'lar oldukça etkin ve verimli bir şekilde kullanılmaktadır [3].

İHA'lar kullanılarak çok alçak uçuşta yüksek hassasiyette elde edilen görüntüler geleneksel hava fotogrametrisinden elde edilen görüntülere göre daha düşük maliyette üretilebilmektedir [4].

Yapılan bir çalışmada Aşağı Dünya diğer adıyla Akhayat obruğunun farklı açılardan çekilen İHA görüntüleri yardımıyla üç boyutlu modelleme çalışmasını yapmışlar ve kontrol noktalarındaki karesel ortalama hata $1.64 \mathrm{~cm}$ olarak bulmuştur. Ayrıca aynı çalışmada yer örnekleme aralığı $1.37 \mathrm{~cm} /$ piksel ortofoto ve $11 \mathrm{~cm} /$ piksel sayısal yükseklik modeli de üretilmiştir [5].

Gaziantep 5.Organize Sanayi Bölgesinde fotogrametrik veri üretimi için İHA görüntüleri kullanılmış ve yer örnekleme aralığ $3.53 \mathrm{~cm}$ olan ortofoto ve $7.06 \mathrm{~cm}$ olan sayısal yüzey modeli elde etmişlerdir. İHA’nın insan yaşamı için tehlikeli ortamlarda uzaktan veri toplama imkanı sunarak anında çözüm üretecek gerçek zamanlı veri kontrolü ve üretimini sağladığı sonucuna varmışlardır [6].

Yaptıkları bir çalışmada İHA ile yüksek hassasiyette sayısal yükseklik modeli üretimi ve ormancılıkta kullanım olanaklarını araştırmışlar ve İHA ile uçuş yüksekliğine bağlı olarak 2,4 cm ile $24 \mathrm{~cm}$ arasında görüntü çözünürlüğe sahip hassas veriler elde edilebildiği tespit 
etmişlerdir. Ayrıca. Ormancılık çalışmalarında, ihtiyaç duyulan coğrafi bilgi sistemi verilerinin elde edilmesinde İHA olanakları kullanımının yarar sağlayacağı düşünülmektedir. SYM (Sayısal Yüzey Modeli) verilerinin hassasiyeti bakımından detaylı olarak değerlendirilen görüntü alımlarının LIDAR ve IFSAR verilerinin sahip olduğu hassasiyete nispeten sahip olmadığı, ancak maliyet bakımından karşılaştıııldığında oldukça verimli alternatif fotogrametrik bir araç olduğu sonucuna varmışlardır [7].

Yaptıkları bir çalışmada Bezariye Hanının fotogrametrik olarak ölçülmesi, üç boyutlu modellenmesi ve gerçek dokuları ile kaplanmasını amaçlamışlardır. İHA ile fotogrametrik teknikler kullanılarak üretilen üç boyutlu modellerin, restorasyon projelerinde altlık olabilecek nitelikleri taşıdığını gözlemişlerdir. Ayrıca bu modellerin İHA'lar yardımıyla fotogrametrik teknikler kullanılarak yapılamsı, fotoğraf çekme olanaklarını artırması ve dolayısı ile dokümantasyonun daha kapsamlı ve gerçekçi olmasına olanak sağlamaktadır. Fotogrametrik tekniklerle elde edilen bu modeller VRML gibi doku kaplama özelliğine sahip üç boyutlu farklı veri formatlarına export edilerek istenilen amaca uygun olarak kullanılabilmektedir. $\mathrm{Bu}$ anlamda fotogrametrik tekniklerin İHA'lar yardımıyla farklı disiplinlere de hizmet edebileceği sonucuna varmışlardır [8].

İnsansız hava araçları ile elde edilen eğik görüntülerden UNESCO tarafindan 2013 yılında dünya kültürel miras listesine alınan "Sacro Monte of Varallo-Sesia” yerleşim yerinin üç boyutlu modelini üretmeyi amaçlamışlardır. Çalışmada düşük maliyetli İHA sistemlerinden elde edilen eğik görüntülerin rahatlıkla kullanıldığı, kültürel mirasları araştırmak ve belgelemek için etkili bir yöntem olduğu, çok kısa sürede karmaşık ve eksisksiz bir bilginin toplanmasına izin verdiği, haritalama ve belgeleme amaçları için büyük avantajlara sahip olduğu sonucuna varmışlardır [9].

Bu çalışmada İHA'larının temel kavramları, İHA'ların tarihsel gelişimi, temel bileşenleri, çalışma prensipleri, sınıflandırılması, kullanım alanları ve Aksaray Üniversitesi Kampüs Camii'nin üç boyutlu modelleme çalışması ve elde edilen sonuçlar yer almaktadır.

\section{2. İNSANSIZ HAVA ARAÇLARI (IHA)}

İnsanız Hava Araçları, boş veya pilotsuz motorlu havasal araçlar olarak tanımlanmaktadır. İHA'ların kontrol mekanizması uzaktan, yarı otomatik, otomatik veya bunların birkaçının birleşiminden oluşmaktadır. İHA'lar diğer hava araçlarıyla karşılaştırıldığında, en önemli fark İHA'larda fiziksel olarak pilotun bulunmamasıdır [10, 11]. İHA'lar, düşük maliyet ile yüksek 
performasa sahip olmasından dolayı sivil ve askeri amaç ve uygulamalar başta olmak üzere birçok havacılık uygulamalarında en önemli teknolojilerden biridir.

Son birkaç yıldır sivil uygulamalarda kullanılan küçük İHA'lar, yarı otomatik ve tam otomatik destekli yazılım ve donanımların gelişmesi ile birlikte boyutları büyümüştür. Buna ek olarak düşük maliyetli ve küçük boyutlardaki Global Konumlama Sistemleri (GPS), sensörler, donanımlar, gövde malzemeleri ve diğer entegre sistemlerin gelişmesi ile birlikte de İHA'ların sivil uygulama alanları gelişmiş ve kullanımını yaygınlaştırmıştır.

İHA'lar, termal, kızıl ötesi, hiperspektral, radar, kimyasal ve biyolojik gibi sensörlere sahip çeşitli görüntüleme cihazları ile entegre edilerek gündüz ve gece görüntü alabilme olanağ 1 sağlayabilmektedir. İnsansız Hava Aracının kullanımı yalnızca uçuşu kapsamamaktadır. Bu kapsamda beş aşamalı çalışma ve kontrol gerekmektedir. Bunlar; uçuş öncesi hazırlık, uçuşa hazırlık ve kontrol, güvenlik denetimi, kalkış ve iniş ve iniş sonrası çalışmalardır. Başarılı bir sonuç için bu aşamaların her biri dikkatlice planlanmalı ve uygulanmalıdır.

İHA'ların tarım, ormancılık, acil durum yönetim, arkeoloji, mimari ve haritacılık gibi birçok disiplinde kullanılması, düşük maliyetli, hızlı ve güvenilir veriler üretmesi gibi birçok avantajı olmasına rağmen dezavantajı da vardır. Bunlar sınırlı yük taşıyabildiklerinden büyük alanları içeren uygulamalarda yetersiz kalmaları, havada kalma sürelerinin az olması, rüzgârlı havalarda uygulama yapma imkânının kısıtlı olması, iniş, kalkış ve uçuş aşamasında yaşanan sıkıntılar olarak sıralamak mümkündür $[11,12]$.

\section{1 İHA'ların Sınıflandırılması}

İHA sistemleri kurumlar, kuruluşlar ve ülkeler tarafından farklı yaklaşımlar türetilerek sınıflandırılmıştır. İHA’lar, Uluslarası İHA Topluluğu (UAV Association) tarafından kullanım türüne göre üç farklı kategoriye ayrılmıştır (Tablo 1). Hava araçlarının her bir tipolojisi performans ve özelliklerine göre alt gruplara ayrılmıştır. Bu özellikler menzil, maksimumum çıkış yüksekliği, uçuş süresi, kütle ve ağırlıktan oluşmaktadır [13].

\section{2 İHA'ların Kullanım Alanları}

Günümüzde, fotogrametri haritacılık alanında oldukça önemli bir yere sahiptir. Fotogrametrik harita üretiminde farklı platformlar kullanılarak görüntü alımı gerçekleştirilmektedir. $\mathrm{Bu}$ bağlamda, İHA teknolojisi yeni bir görüntü alım platformu olarak karşımıza çıkmaktadır. Gerekli sensörler (GPS, Kamera, vb.) ile desteklenen basit İHA'lardan elde edilen verilerin analizi ile gelişmiş haritalar üretebilir. Küçük İHA'lar kolay ve hızlı bir şekilde harekete geçebilir ve kaliteli görüntüler çekebilecek hafif ağırlıktaki dijital kameraları taşıyabilirler. 
Basit GPS ekipmanları İHA verilerinden mekânsal olarak doğruluğu yüksek haritalar oluşturmasını sağlamaktadır [5-7]. Son zamanlarda, dünyanın dört bir yanındaki araştırmacılar, yeni bir teknik olan İHA kullanılarak elde edilen hava görüntülerini çalışmalarına dâhil etmeye başlamışlardır.

Tablo 1. İHA'ların sınıflandırılması.

\begin{tabular}{|l|c|c|c|c|c|}
\hline \multicolumn{1}{|c|}{ İHA KATEGORILERI 1 } & Kısaltma & Menzil (km) & Çıkış Yüksekliği (m) & $\begin{array}{c}\text { Havada Kalış } \\
\text { Süresi (Saat) }\end{array}$ & Kütle (kg) \\
\hline Micro & $\mu($ Micro ) & $<10$ & 250 & 1 & $<5$ \\
\hline Mini & Mini & $<10$ & $150-300$ & $<2$ & 150 \\
\hline Yakın Resim & CR & $10-30$ & 3000 & $2-4$ & 150 \\
\hline Kısa Mesafe & SR & $30-70$ & 3000 & $3-6$ & 200 \\
\hline Orta Mesafe & MR & $70-200$ & 5000 & $6-10$ & 1250 \\
\hline Orta Dayanıklı Derinlikli & MRE & $>500$ & 8000 & $10-18$ & 1250 \\
\hline Düşük Dayanıklı Derinlikli & LADP & $>250$ & $50-9000$ & $0.5-1$ & 350 \\
\hline Düşük Dayanıklı Uzun Derinlikli & LALE & $>500$ & 3000 & 24 & 30 \\
\hline Orta Yükseklik Uzun Dayanılılı & MALE & $>500$ & 14000 & $24-48$ & 1500 \\
\hline
\end{tabular}

İHA'lar ile yükseklik modelleri, termal haritalar, iki boyutlu haritalar ve üç boyutlu modeller olmak üzere çok sayıda farklı harita üretebilir. Eğer bu haritalar doğruluğu yüksek bir şekilde üretilirse, bu haritalardan elde edilen veriler birçok uygulama için kullanılabilir [14].

İHA'ların diğer bazı kullanım alanları; Tarım, ormancılık, arkeoloji ve mimari, çevre, kentsel karayolu trafik izleme, acil durum yönetimi, jeolojik ve meteorolojik araştırmalar, baraj havzalarının ölçümü ve haritalanması, maden sahalarının, taşocaklarının ölçümü ve hacim hesaplamaları, doğal kaynak yönetimi, mera alanların sınıflandırılması ve değerlendirilmesi şeklinde sıralanabilir [15-17].

\section{UYGULAMA}

\subsection{Aksaray Üniversitesi Kampus Camii}

Çalışma kapsamında pilot uygulama objesi olarak Aksaray Üniversitesi Kampüs Cami seçilmiştir. Camii kampüs ana yolu üzerinde ve kampüsün orta kısmında yer almaktadır. Cami $1352 \mathrm{~m}^{2}$ taban alanına sahiptir. Ayrıca Kampüs Cami'nin yüksek bir minare, kubbe, eğik yüzeyler gibi çeşitli ve karmaşık cephelere sahip olması ve cami yüzeylerini kapatacak etrafında herhangi bir yapının mevcut olmaması gibi nedenlerden dolayı 3B model çalışması için iyi bir örnek teşkil etmektedir (Şekil 1). 


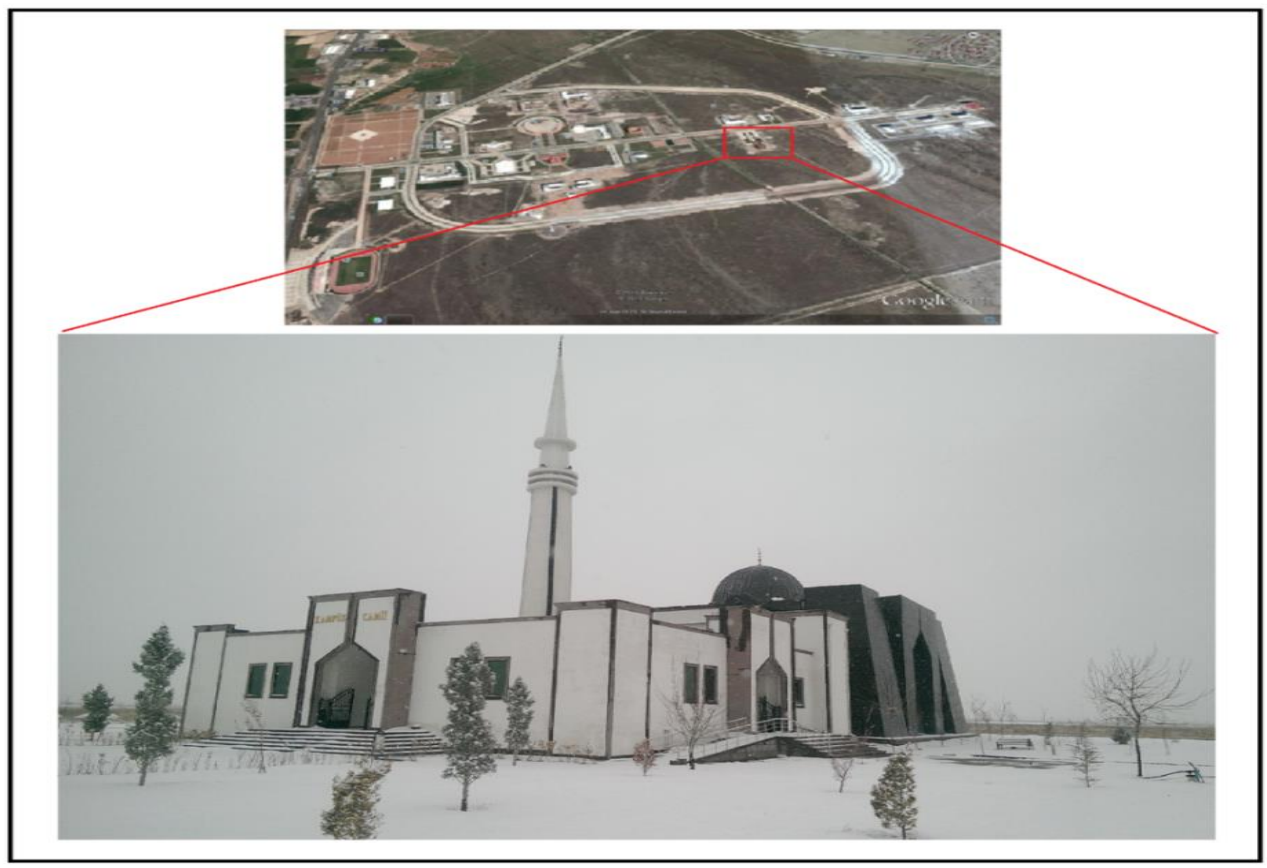

Şekil 1. Aksaray Üniversitesi kampüs uydu görüntüsü (URL 5).

\subsection{Kullanılan Ekipmanlar}

Bu çalışmada çok rotorlu kanatlı İHA kullanılmıştır (Şekil 2). Çalışmada kullanılan İHA, 1000 metreden yüksekte yaklaşık 30-40 dakikalık uçuş süresi sağlayan 12 hücreli lityum polimer pillerle çalışmaktadır. $6000 \times 4000$ piksel çözünürlüğe, 16 mm odak uzaklığına, $23.5 \times 15.6$ mm sensör boyutuna ve $4 \times 4 \mu \mathrm{m}$ piksel boyutuna sahip bir kamera kullanılmıştır. GPS /GLONASS uyduları tarafindan yayınlanan L1 / G1 ve L2 / G2 frekanslarını alabilen iki Topcon GR 3 GPS alıcısı kullanılmıştır.

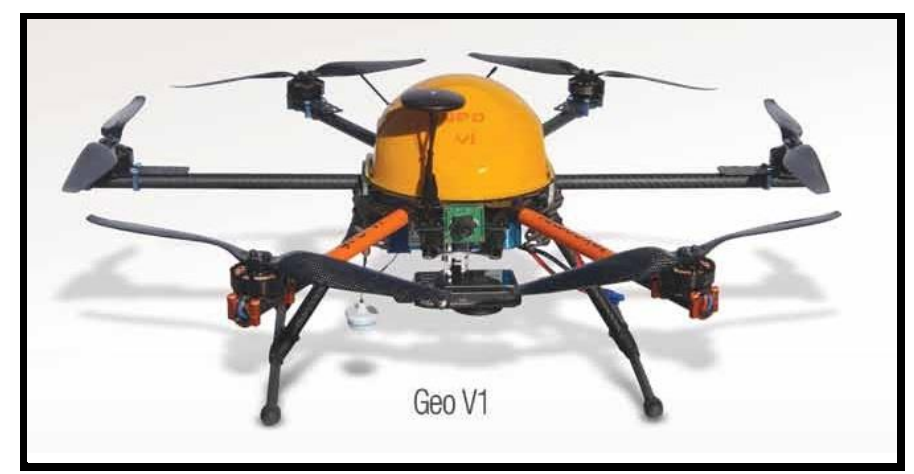

Şekil 2. Uygulamada Kullanılan IHA

\section{3 Çalışma Alanı Uçuş Planı}

Uçuş planını oluşturmak amacıyla Mission Planner yazılımı kullanılmıştır. Uçuş, görüntüleri iki ayrı yükseklikten toplanmak üzere planlanmıştır. İlk olarak uçuş yüksekliği $50 \mathrm{~m}$ seçilmiş ve uçuş planı yapılmıştır. Bu uçuş işlemi 04:45 dakika sürmüş ve toplam 89 resim çekilmiştir. Daha sonra uçuş yüksekliği olarak 100 m seçilmiş ve uçuş planlaması yapılmıştır. Toplam 06:55 dakika süren bu uçuşta toplam 83 resim çekilmiştir. İki yükseklikte de İHA 
görüntülerinde karşılaşılabilecek kalite sorunları nedeniyle aynı kontrol noktaları ve donanım kullanılmıştır. İki uçuş içinde, ileri bindirme \%80, yan bindirme $\% 60$ ve uçuş hızı $5 \mathrm{~m} / \mathrm{s}$ dir (Tablo 2).

Tablo 2. Uçuş Planı

\begin{tabular}{|c|c|c|c|c|c|c|}
\hline & $\begin{array}{c}\text { Yükseklik } \\
(\mathbf{m})\end{array}$ & $\begin{array}{c}\text { Fotoğraf } \\
\text { Sayıları }\end{array}$ & $\begin{array}{c}\text { Arazideki } \\
\text { Baz (m) }\end{array}$ & $\begin{array}{c}\text { Seritler Arası } \\
\text { Mesafe (m) }\end{array}$ & $\begin{array}{c}\text { Uçus } \\
\text { Süresi(dk) }\end{array}$ & $\begin{array}{c}\text { Resim Çekme } \\
\text { Süresi (sn) }\end{array}$ \\
\hline Uçuş 1 & 50 & 89 & 10 & 29.38 & $4: 05$ & 1.95 \\
\hline Uçuş 2 & 100 & 83 & 20 & 58.75 & $6: 55$ & 3.99 \\
\hline
\end{tabular}

\subsection{Yer Kontrol Noktaları}

Çalışmada İHA verilerini coğrafi olarak referanslandırmak için uygun dağılımda cami üzerinde ve çevresinde bulunan 24 yer kontrol noktası işaretlenmiştir. (Şekil 4.3). Yer kontrol noktalarının koordinatlarının TUREF/TM33 sisteminde elde edilebilmesi için iki adet Topcon GR3 GNSS alıcısı kullanılmıştır ve alıcılardan biri sabit diğeri gezici olarak konfigüre edilerek ölçmeler tamamlanmıştır (Şekil 3).

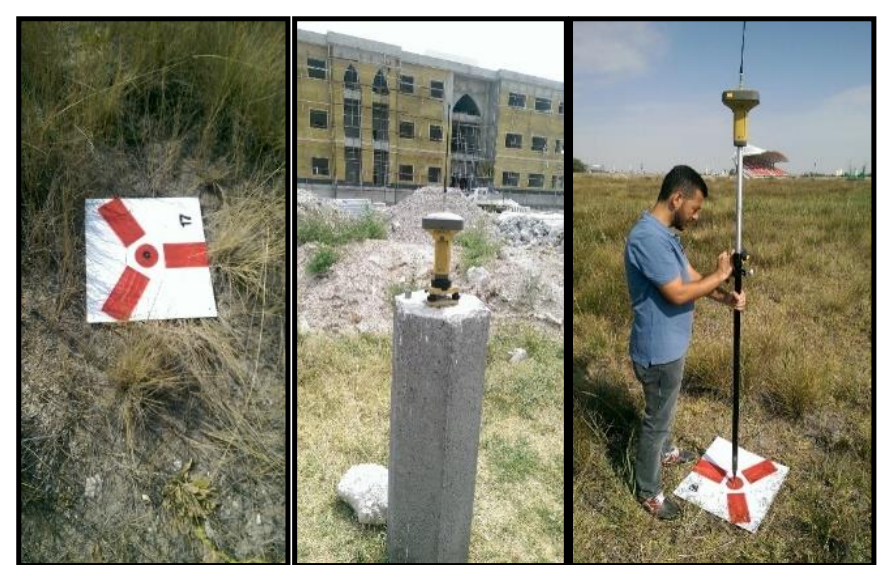

Şekil 3. a) Yer kontrol noktası b) Sabit GNSS alıcısı c) Gezici GNSS alıcısı

\section{5 Çalışmada Kullanılan Yazılım}

$\mathrm{Bu}$ çalışmada AgiSoft PhotoScan yazılımının profesyonel sürümü kullanılmıştır. Büyük projelerde (100 fotoğraf ve daha fazla) hesaplama yapabilmek için 64 bit işletim sisteminde en az 6 GB RAM' e sahip bir donanıma sahip olunması önerilmektedir. Uygulamanın ilk adımı yazılımda fotoğraflar arasındaki ortak noktaları bulduktan sonra bunları otomatik olarak eşleştirerek sıralamaktır. Ayrıca her fotoğrafta kameranın yerini belirleyerek kamera kalibrasyon parametrelerini hesaplamaktadır. Fotoğrafların bir birine bağlanması bittikten sonra, yazılım iç yöneltme parametreleri ve kamera konumları ile ilişkilendirilmiş bir dizi seyrek nokta bulutu oluşturmaktadır. Nokta bulutu tam olarak bir dizi noktanın üç boyutlu bir uzayda koordinat bilgisine ek olarak renk bilgisinin de bulunmasıdır.

\section{6. İHA Görüntülerinin Değerlendirmesi}


Çalışmada 50 m ve 100 m yükseklikten uçularak elde edilen İHA görüntüleri her iki uçuş yüksekliği için düşük ve orta seviye olmak üzere iki doğruluk için değerlendirme yapılmıştır. Kullanılan bilgisayar konfigürasyonu yüksek doğruluğa izin vermemiştir. Üretilecek modelin doğruluğunu doğrudan etkileyeceği için resimler üzerinde kırpma, döndürme veya yeniden boyutlandırma gibi değişiklikler yapılmamıştır.

Fotoğrafların seçilmesi ve yazılıma yüklenmesinden sonraki ilk aşamada fotoğrafların yöneltme işlemleri yapılmıştır. Çalışma bölgesine ait İHA görüntüleri PhotoScan yazılımı örtüşen fotoğraflar üzerindeki ortak noktaları otomatik olarak aramakta ve eşleştirmeyi gerçekleştirmekte, her resim çekme anında kameranın konumunu belirlenmektedir (Şekil 4) ve bu aşamada kamera kalibrasyon parametreleri tanımlanmaktadır.

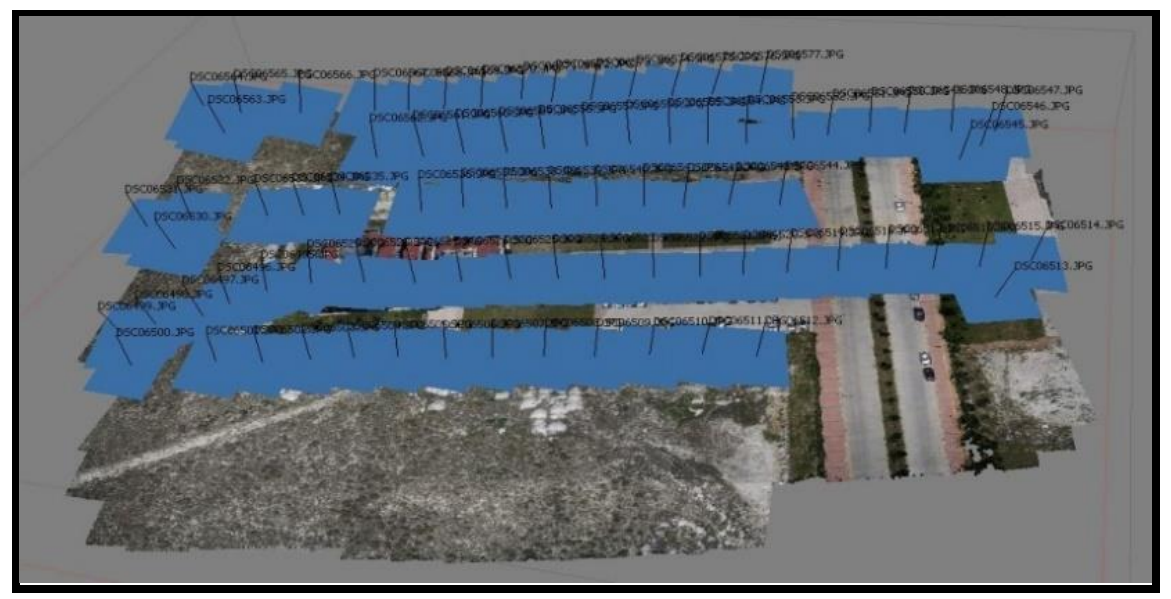

Şekil 4. Kamera konumları

Bir sonraki aşama İHA görüntülerinde bulunan Yer Kontrol Noktalarının (YKN) işaretlenmesidir (Şekil 5). İHA' lardan elde edilen görüntüler üzerinden çok yüksek yoğunlukta nokta verisi üretilebilmektedir. Şekil 6'da $50 \mathrm{~m}$ ve $100 \mathrm{~m}$ yükseklikten uçularak elde edilen İHA görüntüleri ile düşük ve orta olmak üzere her iki doğrulukta oluşturulan yoğun nokta bulutları görülmektedir.

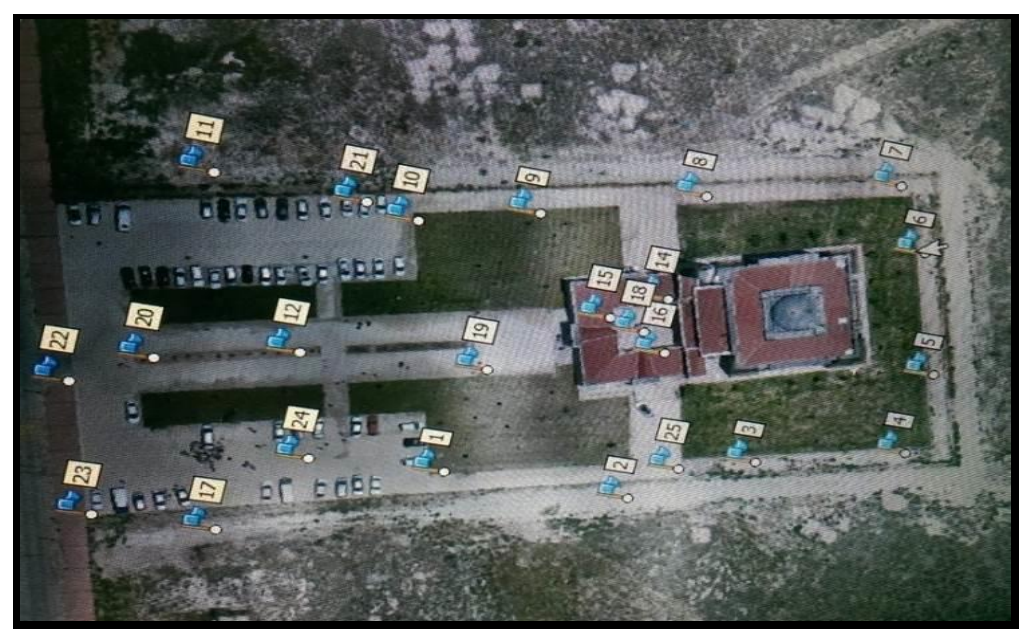

Şekil 5. Yer kontrol Noktaları. 


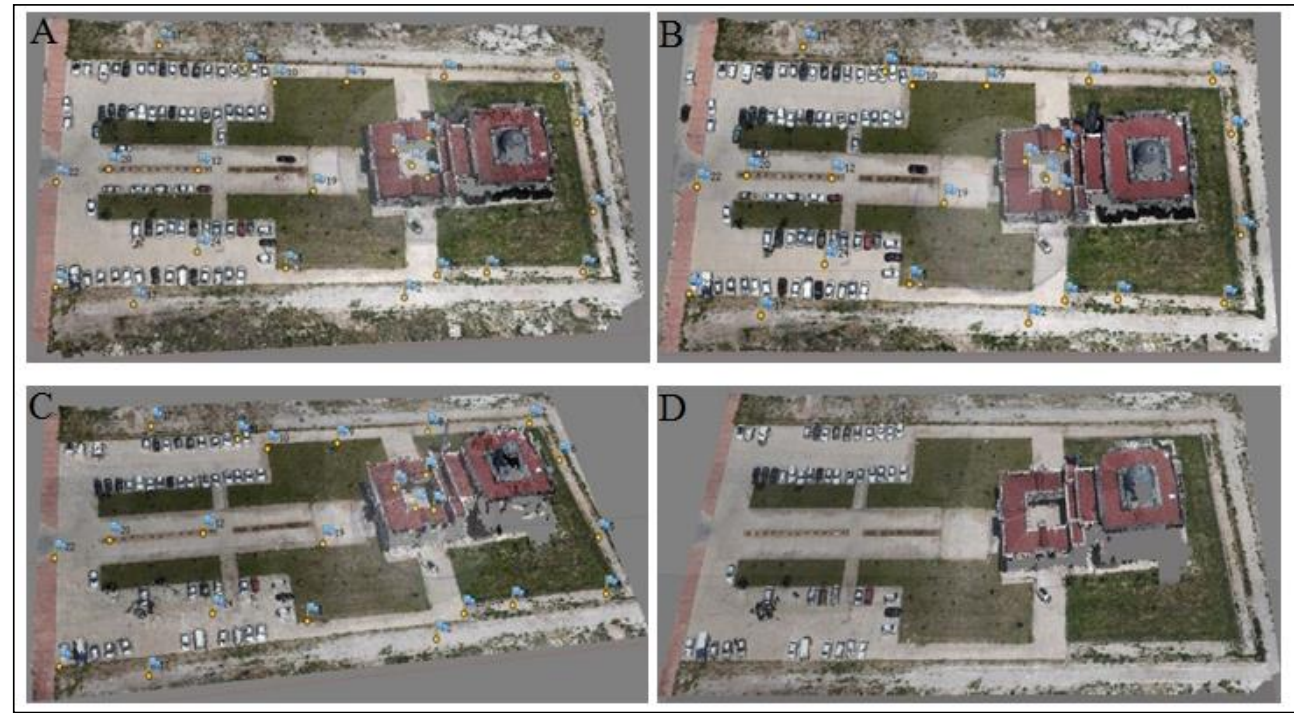

Şekil 6. Yoğun nokta bulutu (A) 50 m yükseklik düşük doğruluk, (B) $50 \mathrm{~m}$ yükseklik orta doğruluk (C) $100 \mathrm{~m}$ yükseklik düşük doğruluk (D) 100 m yükseklik orta doğruluk

Doku eşleme modu, nesne dokusunun doku atlasında nasıl paketleneceğini belirlemektedir. Doğru doku eşleme modu seçimi en iyi doku paketlemeyi ve dolayısıyla nihai modelin daha iyi görsel kalitesini elde etmede yardımcı olmaktadır. Bu çalışmada elde edilen doku model Şekil 7'de görülmektedir.
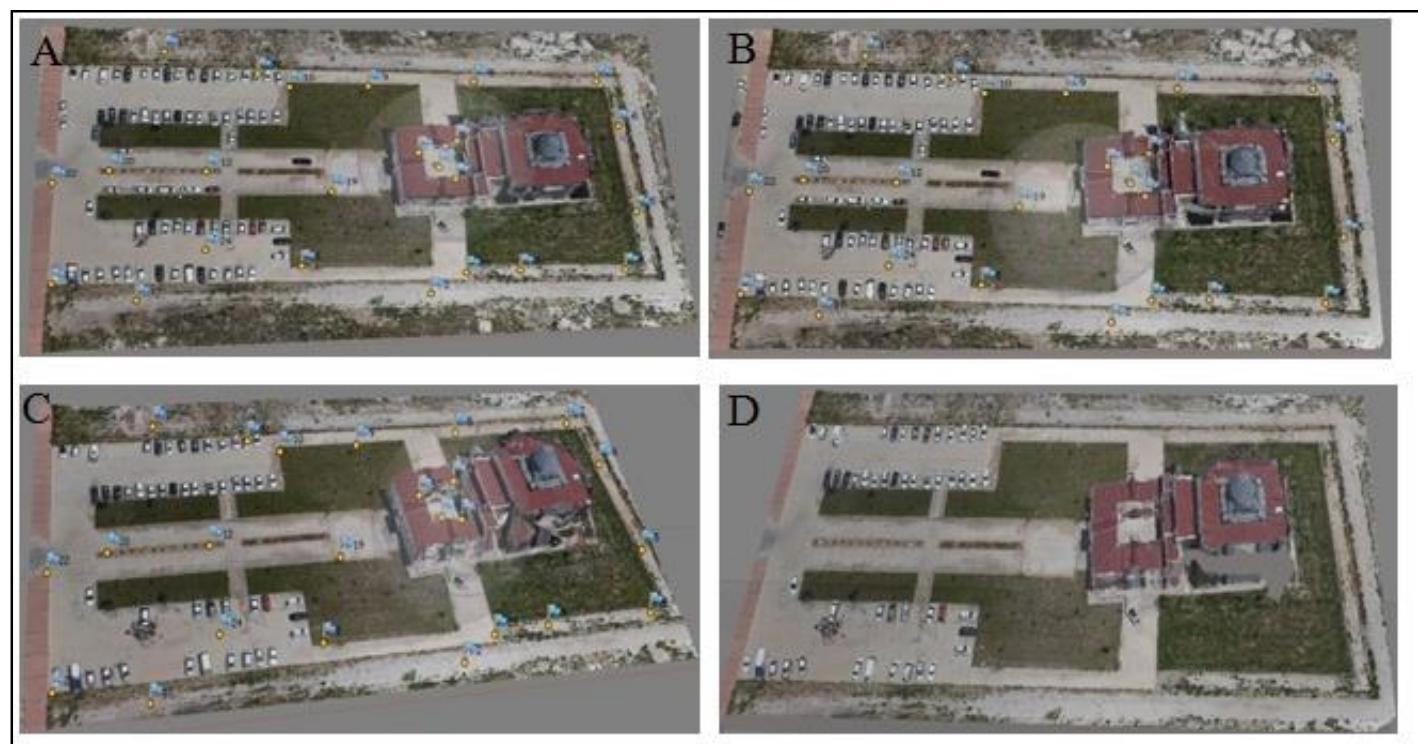

Şekil 7. Doku model (A: $50 \mathrm{~m}$ yükseklik düşük doğruluk B: $50 \mathrm{~m}$ yükseklik orta doğruluk C: $100 \mathrm{~m}$ yükseklik düşük doğruluk D: $100 \mathrm{~m}$ yükseklik orta doğruluk).

Sayısal yükseklik modeli (SYM), model yüzeyini yükseklik değerlerinin düzenli bir grid halinde temsil etmektedir. Her iki uçuş için elde edilen sayısal yükseklik modeli Şekil 8'de verilmiştir. Sayısal yükseklik modeli elde edildikten sonra çalışma alnının ortofoto haritası üretilmiştir. Elde edilen ortofoto haritalar Şekil 9'da görülmektedir. 


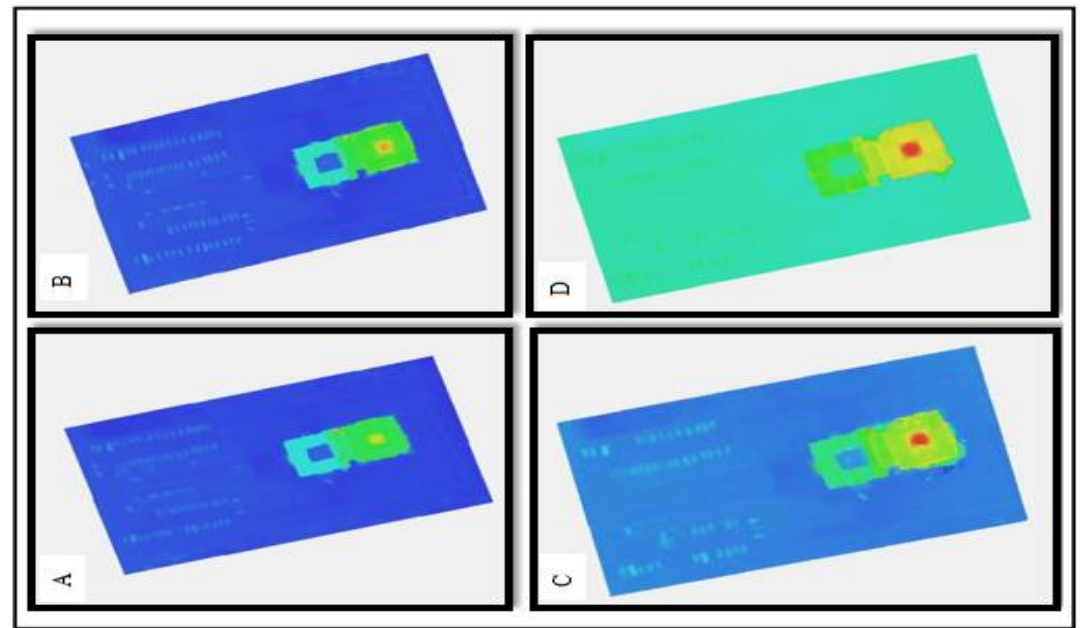

Şekil 8 Sayısal yükseklik modeli (A: $50 \mathrm{~m}$ yükseklik düşük doğruluk B: $50 \mathrm{~m}$ yükseklik orta doğruluk C: $100 \mathrm{~m}$ yükseklik düşük doğruluk D: 100 m yükseklik orta doğruluk).

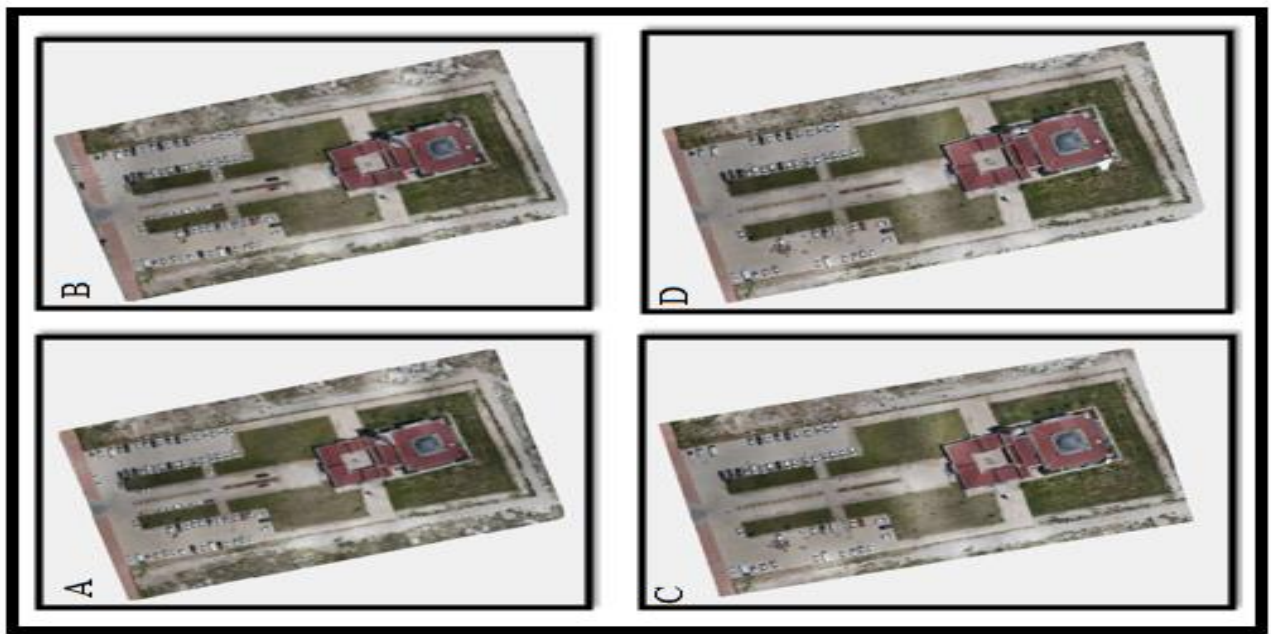

Şekil 9. Ortofoto (A: $50 \mathrm{~m}$ yükseklik düşük doğruluk B: $50 \mathrm{~m}$ yükseklik orta doğruluk C: $100 \mathrm{~m}$ yükseklik düşük doğruluk D: $100 \mathrm{~m}$ yükseklik orta doğruluk).

\section{7. Üç Boyutlu Modelin Çıkartılması}

PhotoScan yazılımı yapılan işlemleri farklı formatlarda ve gösterimlerde (seyrek ve yoğun nokta bulutu, kamera kalibrasyonu ve kamera yöneltme parametreleri, yüzey modeli, sayısal yükseklik modeli ve ortofoto) üretmemize olanak sağlamaktadır. Bu çalışmanın temel konusu olan Aksaray Üniversitesi Kampüs Camii'ne ait, yoğun nokta bulutu sınıfları Şekil 10'da, yoğun nokta bulutu Şekil 11'de, ve üç boyutlu modeli Şekil 12'de görülmektedir.

\section{8 Üç Boyutlu Modelde Doğruluk}

Çalışma kapsamında üretilen 3B modele ait konum doğruluğunun belirlenmesi için Camii üzerinde belirlenen noktalar yersel ölçme yöntemleri kullanılarak ölçmeler yapılmış ve bu noktalara ait koordinat değerleri hesaplanarak cephe uzunlukları ve cephe yükseklikleri belirlenmiştir (Şekil 13 ve 14). Yersel ölçme işlemi için elektronik ölçme aleti kullanılarak 
noktalara ait elde yatay açı, düşey açı ve eğik mesafe değerleri kullanılarak noktalara ait koordinatlar hesaplanmıştır (Tablo 3).
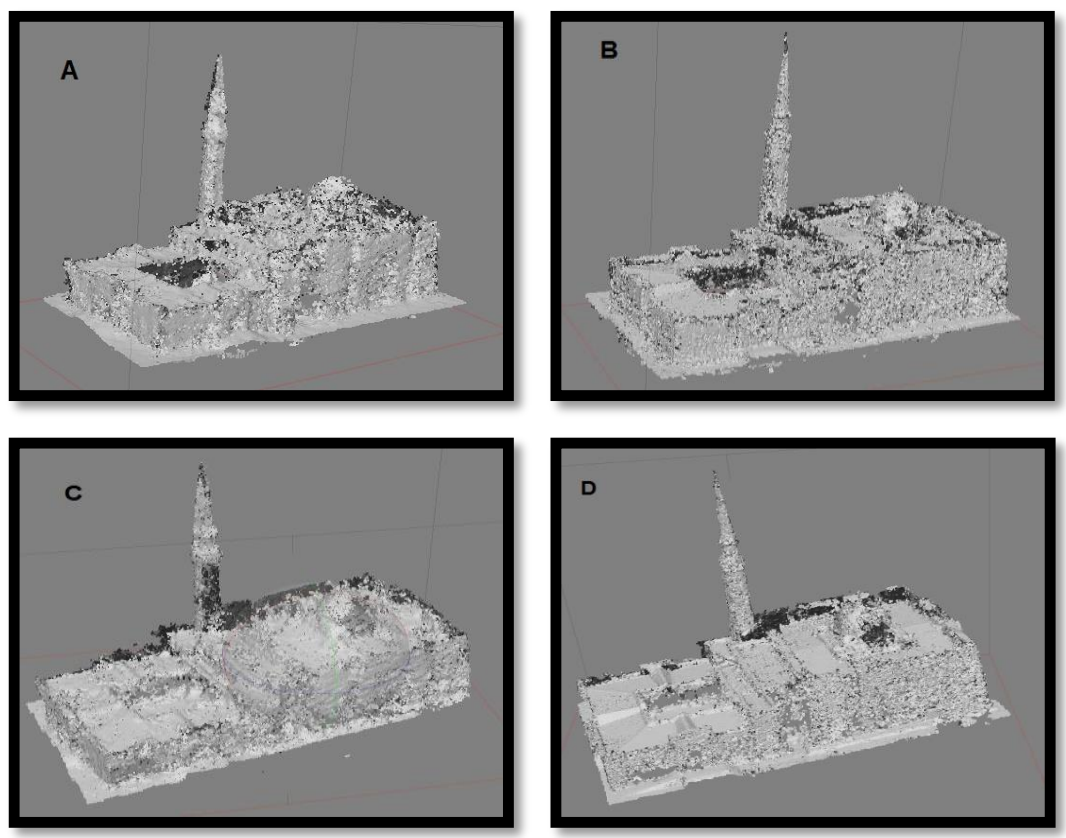

Şekil 10. Aksaray Üniversitesi kampüs camii yoğun nokta bulutu sınıfları (A: $50 \mathrm{~m}$ yükseklik düşük doğruluk B: $50 \mathrm{~m}$ yükseklik orta doğruluk C: $100 \mathrm{~m}$ yükseklik düşük doğruluk D: $100 \mathrm{~m}$ yükseklik orta doğruluk).
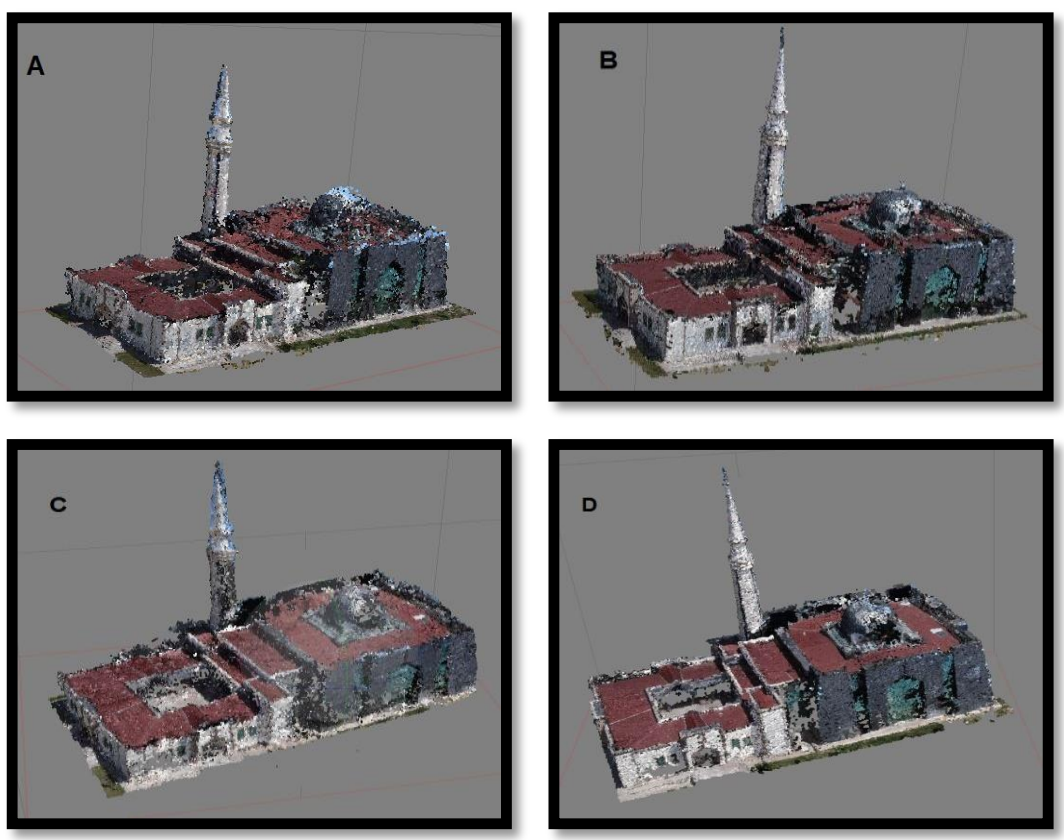

Sekil 11. Aksaray Üniversitesi kampüs camii yoğun nokta bulutu (A: 50m yükseklik düşük doğruluk B: 50m yükseklik orta doğruluk C: 100m yükseklik düşük doğruluk D: 100m yükseklik orta doğruluk). 

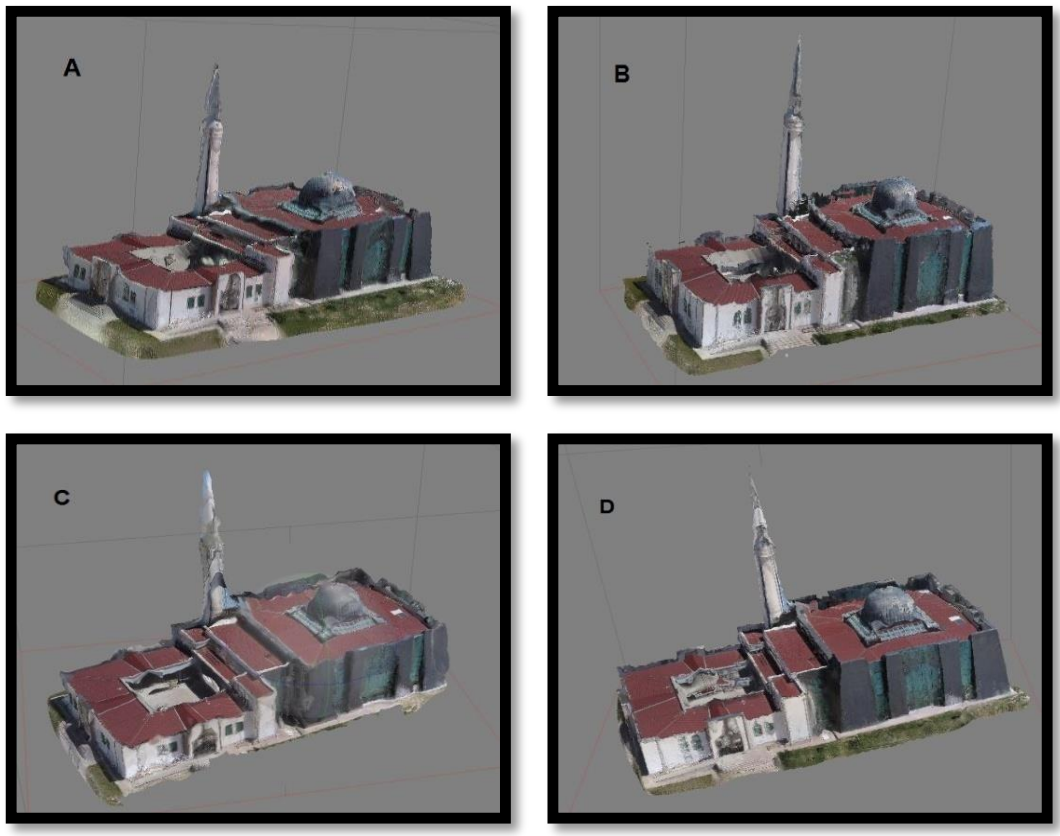

Şekil 12. Aksaray Üniversitesi kampüs camii üç boyutlu model (A: $50 \mathrm{~m}$ yükseklik düşük doğruluk B: $50 \mathrm{~m}$ yükseklik orta doğruluk C: $100 \mathrm{~m}$ yükseklik düşük doğruluk D: $100 \mathrm{~m}$ yükseklik orta doğruluk).

Tablo 3. Ölçülen koordinat değerleri

\begin{tabular}{|c|c|c|c|}
\hline Nokta No & $\mathbf{X}$ & $\mathbf{Y}$ & $\mathbf{Z}$ \\
\hline 1 & 586747.631 & 4244257.139 & 990.494 \\
\hline 2 & 586745.176 & 4244258.154 & 990.492 \\
\hline 3 & 586740.015 & 4244260.192 & 990.493 \\
\hline 4 & 586737.840 & 4244261.052 & 990.490 \\
\hline 5 & 586736.028 & 4244262.334 & 990.478 \\
\hline 6 & 586731.086 & 4244264.300 & 990.487 \\
\hline 7 & 586714.935 & 4244270.179 & 990.957 \\
\hline 8 & 586706.587 & 4244272.433 & 990.409 \\
\hline 10 & 586702.444 & 4244264.541 & 990.966 \\
\hline 11 & 586700.656 & 4244260.038 & 990.941 \\
\hline 12 & 586697.901 & 4244251.113 & 990.412 \\
\hline 13 & 586714.912 & 4244243.494 & 990.401 \\
\hline 14 & 586728.489 & 4244237.970 & 990.525 \\
\hline 15 & 586728.491 & 4244237.946 & 1002.357 \\
\hline 16 & 586720.959 & 4244241.268 & 990.558 \\
\hline 17 & 586720.845 & 4244243.190 & 1027.079 \\
\hline 18 & 586714.783 & 4244244.195 & 990.400 \\
\hline 19 & 586715.208 & 4244244.274 & 996.058 \\
\hline 20 & 586714.943 & 4244243.471 & 998.862 \\
\hline 21 & 586697.896 & 4244251.110 & 996.606 \\
\hline 22 & 586700.408 & 4244259.819 & 997.588 \\
\hline
\end{tabular}

Jedeozik olarak ölçülen noktalardan oluşan cephe uzunlukları ve yükseklikleri elde edilen 3B model üzerinden de ölçülerek karşılaştırılmıştır (Tablo 4). Oluşturulan modele ait toplam hata miktarları Tablo 5'de gösterilmiştir. Bilindiği gibi objelerin üç boyutlu modellerin elde edilmesinde obje üst yüzeyleri için düşey resimler, obje yan yüzeyleri için eğik resimlerin fotogrametrik teknikle çekilmiş olması gerekmektedir. Bu çalışmada İHA ile eğik resim çekimi 
yapılmamış ve bu nedenle camii’ye ait üç boyutlu modelin yan yüzeylerinde ve minaresinde boşluklar oluşmuştur.

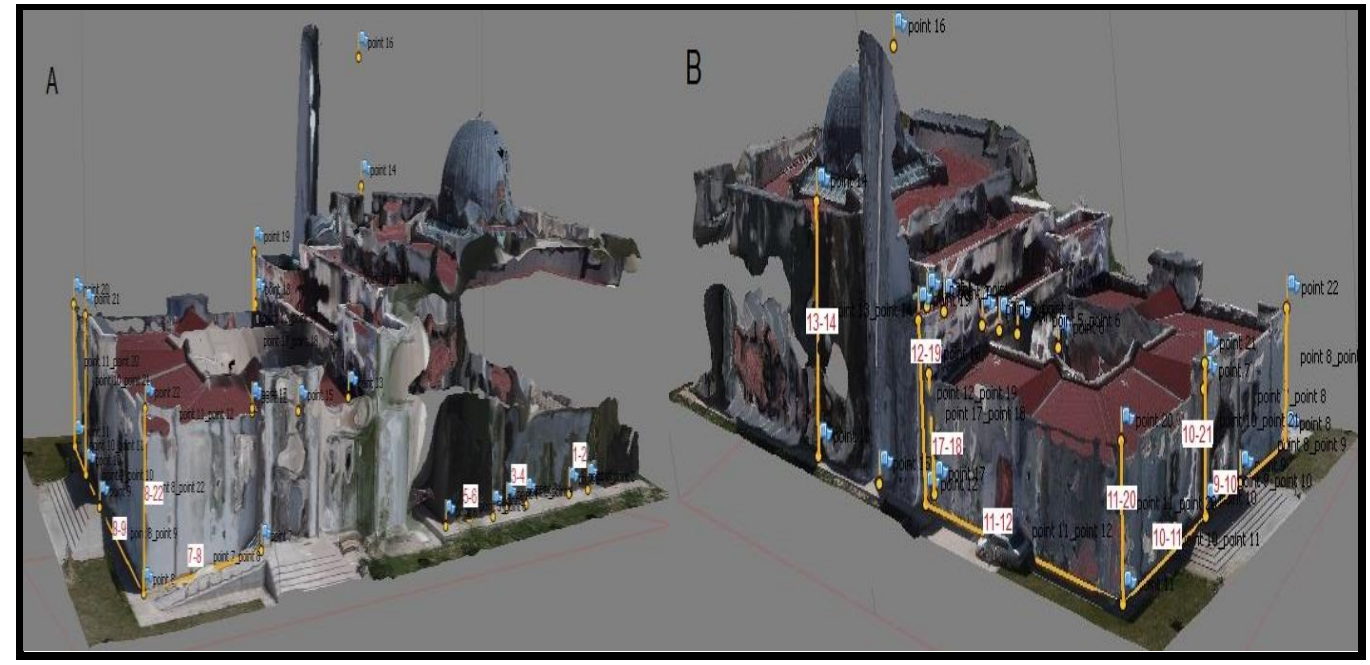

Şekil 13. A,B: Karşılaştırma yapılan cepheler 1

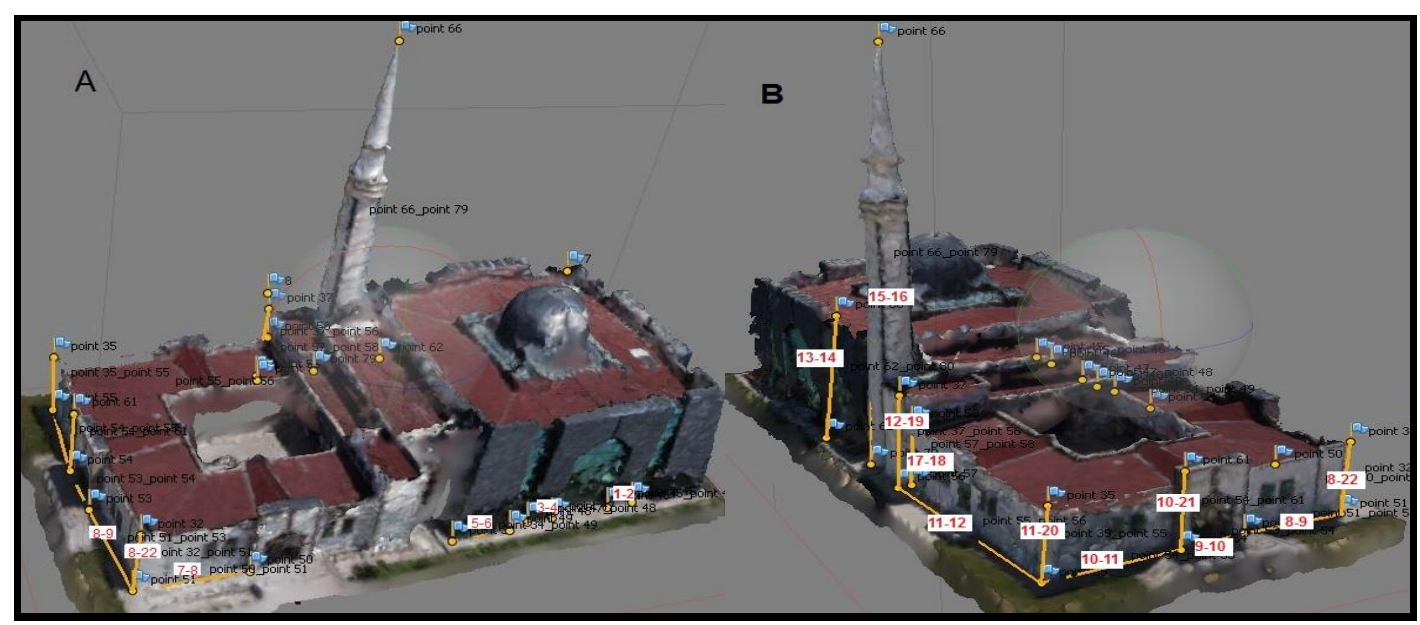

Şekil 14. A,B: Karşılaştırma yapılan cepheler 2

Tablo 4. Cephe uzunluklarının karşılaştırılması

\begin{tabular}{|c|c|c|c|}
\hline Cepheler & $\begin{array}{c}\text { Model üzerinden Ölçülen } \\
\text { Uzunluk (m) }\end{array}$ & $\begin{array}{c}\text { Yersel Ölçme Yöntemi ile } \\
\text { Hesaplanan Uzunluk (m) }\end{array}$ & Fark (m) \\
\hline $1-2$ & 2.63 & 2.66 & 0.03 \\
\hline $3-4$ & 2.36 & 2.34 & 0.02 \\
\hline $5-6$ & 5.37 & 5.32 & 0.05 \\
\hline $7-8$ & 8.69 & 8.63 & 0.06 \\
\hline $8-9$ & 8.97 & 8.93 & 0.04 \\
\hline $9-10$ & 4.93 & 4.85 & 0.08 \\
\hline $10-11$ & 9.31 & 9.35 & 0.04 \\
\hline $11-12$ & 18.62 & 18.25 & 0.37 \\
\hline $8-22$ & 6.57 & 5.97 & 0.40 \\
\hline $10-21$ & 6.62 & 6.65 & 0.03 \\
\hline $11-20$ & 6.45 & 6.19 & 0.26 \\
\hline $12-19$ & 8.40 & 8.46 & 0.06 \\
\hline $17-18$ & 5.55 & 5.66 & 0.11 \\
\hline $15-16$ & 37.02 & 36.52 & 0.50 \\
\hline $13-14$ & 11.96 & 11.83 & 0.13 \\
\hline
\end{tabular}


Tablo 5. Elde edilen üç boyutlu modeldeki hatalar

\begin{tabular}{|c|c|c|c|c|c|c|}
\hline 势 & 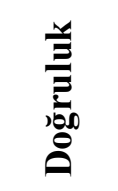 & Alan & $\begin{array}{c}\text { Toplam } \\
\text { XY Hata }(m)\end{array}$ & $\begin{array}{c}\text { Toplam } \\
\text { Z Hata }(m)\end{array}$ & $\begin{array}{c}\text { Toplam } \\
\text { Hata }(m)\end{array}$ & $\begin{array}{c}\text { Toplam } \\
\text { Hata (pik.) }\end{array}$ \\
\hline \multirow{4}{*}{ हี } & \multirow{2}{*}{ 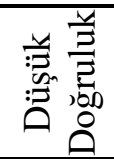 } & Uygulama Alanı & 0.023239 & 0.118695 & 0.120949 & 0.959 \\
\hline & & Sadece Bina & 0.012407 & 0.011245 & 0.016745 & 0.191 \\
\hline & \multirow{2}{*}{ 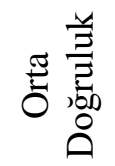 } & Uygulama Alanı & 0.018258 & 0.017027 & 0.024966 & 0.343 \\
\hline & & Sadece Bina & 0.016387 & 0.026927 & 0.031522 & 0.177 \\
\hline \multirow{4}{*}{ छ్ } & \multirow{2}{*}{ 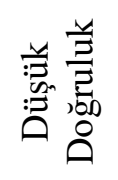 } & Uygulama Alanı & 0.035330 & 0.082637 & 0.089873 & 1.167 \\
\hline & & Sadece Bina & 0.017713 & 0.013246 & 0.022118 & 0.269 \\
\hline & \multirow{2}{*}{ 丞 } & Uygulama Alanı & 0.022312 & 0.069042 & 0.072557 & 0.624 \\
\hline & & Sadece Bina & 0.017744 & 0.013037 & 0.022019 & 0.253 \\
\hline
\end{tabular}

\section{SONUÇLAR}

$\mathrm{Bu}$ çalışmada Aksaray Üniversitesi Camii için üç boyutlu model İHA ile kameranın yeryüzüne dik konumunda çekilen resimlerin analiz edilmesi sonucunda elde edildi. 3B modelin oluşturulması iki farklı uçuş yüksekliğinden elde edilen görüntüler ile kullanılmıştır.

$\mathrm{Bu}$ çalışma kapsamında üretilen 3B modelin doğruluğunun belirlenmesi amacı ile Camiiye ait bazı yatay ve düşey cephelerin uzunlukları yersel ölçme tekniği ile ölçüldü. Yine aynı cephelerin oluşturulan model üzerinden de ölçümü yapıldı. Yapılan karşılaştırma sonrasında farkların 2-50 cm arasında değişiklik gösterdiği gözlemlenmiştir. Üç cephede farklar $20 \mathrm{~cm}$, $37 \mathrm{~cm}$ ve $50 \mathrm{~cm}$ elde edilmiştir. İHA ile eğik resimler çekilmediği için üç boyutlu modelin tamamlama ölçüleri yersel çekilen resimlerle giderilmeye çalışılmış ancak yerden çekilen resimlerdeki eğiklik açısı örneğin camiinin minaresinde olduğu gibi gereğinden fazla olduğu için üç boyutlu modellemenin tam yapılamadığ görülmektedir.

PhotoScan yazılımı ile iki farklı uçuş yüksekliklerinden elde edilen veriler iki farklı doğrulukta (düşük ve orta) değerlendirilmiştir. $50 \mathrm{~m}$ uçuş yüksekliği için düşük doğrulukta yapılan değerlendirmede en küçük konum hatası $1.24 \mathrm{~cm}$, en küçük yükseklik hatası 1.12 $\mathrm{cm}$, en büyük konum hatası $2.32 \mathrm{~cm}$ ve en büyük yükseklik hatası $1.18 \mathrm{~cm}$; orta doğrulukta yapılan değerlendirmede en küçük konum hatası $1.63 \mathrm{~cm}$, en küçük yükseklik hatası 1.70 cm, en büyük konum hatası $1.82 \mathrm{~cm}$ ve en büyük yükseklik hatası $2.69 \mathrm{~cm}$ bulunmuştur. 100 m uçuş yüksekliği düşük doğrulukta yapılan değerlendirmede en küçük konum hatası 1.77 
cm, en küçük yükseklik hatası $1.32 \mathrm{~cm}$, en büyük konum hatası $3.53 \mathrm{~cm}$ ve en büyük yükseklik hatası $8.26 \mathrm{~cm}$, orta doğrulukta yapılan değerlendirmede en küçük konum hatası $1.77 \mathrm{~cm}$, en küçük yükseklik hatası $1.30 \mathrm{~cm}$, en büyük konum hatası $2.23 \mathrm{~cm}$ ve en büyük yükseklik hatası $6.90 \mathrm{~cm}$ bulunmuştur. Toplam ortalama hata $50 \mathrm{~m}$ uçuş yüksekliği için 4.85 cm, $100 \mathrm{~m}$ uçuş yüksekliği için ise $5.16 \mathrm{~cm}$ bulunmuştur.

Her iki uçuş sonuçlarında binanın bazı bölümlerinde özellikle minare gibi yüksek noktalarında boşluklar görülmüştür, bu sorun tüm hava fotogrametrisinde (İHA ile) gerçekleşebilmektedir. Çünkü bu çalışmada kullanılan İHA ile sadece dikey fotoğraf çekimleri yapılabilmekte ve dolayısı ile minareye ait net bir 3B model elde edilememiştir. Uçuş planlamasının objede boşluk kalmayacak şekilde yapılması ve gerektiğinde eğik resimlerinde çekilmesi gerekmektedir. Şekil 13 ve Şekil 14 arasındaki modellerde görüldüğü gibi Camiinin üç boyutlu modellerinde boşluklar oluşmuştur. Bu boşluklar yerden çekilen resimler yardımıyla giderilmeye çalışılmıştır. İHA ile yapılacak üç boyutlu modelleme çalışmalarında düşey resimlerin yanı sıra eğik resimlerin de çekilmesi gerektiği ve uçuş planlamasının buna göre yapılmasının gerektiği ortaya çıkmıştır.

Sonuçlar incelendiğinde bu çalışmada en iyi sonuç 50 metre uçuş yüksekliği ile elde edilen üç boyutlu modelden elde edilmiş ve toplam hataların daha az çıktığı gözlemlenmiştir.

\section{KAYNAKLAR}

[1] K. N. Tahar, "A New Approach On Slope Data Acquisition Using Unmanned Aerial Vehicle". IJRRAS, (3) 13, 2012, 780-785.

[2] Lucintel, 2011. "Growth Opportunity in Global UAV Market". Accessed July 1, 2012, at www.lucintel.com/LucintelBrief/UAVMarketOpportunity.pdf.

[3] M. Bryson, and S. Sukkarieh, "Vehicle Model-Aided Inertial Navigation for a UAV Using Low-Cost Sensors", in Proc. Australasian Conf. on Robotics and Automation, Canberra, Australia, 2004.

[4] S. Esposito, P. Fallavollita, W. Wahbeh, C. Nardinocchi, and M. Balsi, "Performance Evaluation Of UAV Photogrammetric 3D Reconstruction". IGARSS 2014.

[5] M. Yakar ve Y. Doğan,” Silifke Aşağı Dünya Obruğunun İHA Kullanılarak Üç Boyutlu Modellenmesi”, Afyon Kocatepe Üniversitesi Fen ve Mühendislik Bilimleri Dergisi, 2017, özel sayı, 94-101

[6] I. Özemir, ve, M. Uzar, “İHA İle Fotogrametrik Veri Üretimi", VI. UZAL-CBS Sempozyumu, 5-7 Ekim 2016, Adana

[7] M. Akgül, H. Yurtseven, M. Demir, A.E. Akay, S. Gülci ve T. Öztürk, "İnsansız Hava Araçları ile Yüksek Hassasiyette Sayısal Yükseklik Modeli Üretimi ve Ormancılıkta Kullanım Olanakları", Journal of the Faculty of Forestry Istanbul University, 2016, 66(1): 104-118. 
[8] M. Yakar, A.S.Toprak, A. Ulvi ve M. Uysal "Konya Beyşehir Bezariye Hanının (Bedesten) İHA ile Fotogrametrik Teknik Kullanılarak Üç Boyutlu Modellenmesi”, 15. Harita Bilimsel ve Teknik Kurultayı, 25-28 Mart 2015, Ankara.

[9] A. Lingua, F. Noardo, A. Spanò, , S. Sanna, and F. Matrone, "3D Model Generation Using Oblique Images Acquired By Uav", The International Archives of the Photogrammetry, Remote Sensing and Spatial Information Sciences, Volume XLII-4/W2, 2017 FOSS4G-Europe 2017 - Academic Track, 18-22 July 2017, Marne La Vallée, France

[10]H. Eisenbeiss, "A mini unmanned aerial vehicle (UAV): system overview and image acquisition". International Archives of Photogrammetry, Remote Sensing and Spatial Information Sciences, vol. XXXVI, part 5/W1, on CD-ROM, 2004.

[11]K. S. Rawat, and E. E. Lawrence "A mini-UAV VTOL Platform for Surveying Applications". International Journal of Robotics and Automation (IJRA), (3), 4, 2014, 259267.

[12]H. Eisenbeiss. and, M. Sauerbier," Investigation of UAV systems and flight modes for photogrammetric applications", The Photogrammetric Record, 26(136), 2011,400-421.

[13] A.B. Haser, "Bu insansız hava aracından daha önce yapmamış mıydık?”, Bilim ve Teknik Dergisi, Aralık sayısı, 2010.

[14]F. Greenwood,"Drones And Aerial Observation: New Technologies For Property Rights, Human Rights, And Global Development", Chapter Number 4, Cover Illustration And Interior Illustrations AreValerie Altounian, 2015.

[15] M. L. Brutto, A. Garraffa and P. Meli, "UAV Platforms For Cultural Heritage Survey: First Results". ISPRS Annals of the Photogrammetry, Remote Sensing and Spatial Information Sciences, Volume II-5, 2014 ISPRS Technical Commission V Symposium, 23 - 25 June 2014, Riva del Garda, Italy.

[16] T. Nakano, I. Kamiya M.Tobita, J. Iwahashi and H. Nakajima "Landform Monitoring In Active Volcano By UAV and Sfm-Mvs Technique", The International Archives of the Photogrammetry, Remote Sensing and Spatial Information Sciences, Volume XL-8, 2014 ISPRS Technical Commission VIII Symposium, 09 - 12 December 2014, Hyderabad, India.

[17]H. Chao, , Y. Cao and, Y. Chen "Autopilots for Small Unmanned Aerial Vehicles: A Survey,” Int. J. Control Autom. Syst. 8(1), 36-44 (2010). 